Supplement of Biogeosciences, 14, 989-1001, 2017

http://www.biogeosciences.net/14/989/2017/

doi:10.5194/bg-14-989-2017-supplement

(C) Author(s) 2017. CC Attribution 3.0 License.

(c) (i)

Supplement of

\title{
Abiotic versus biotic controls on soil nitrogen cycling in drylands along a $3200 \mathrm{~km}$ transect
}

Dongwei Liu et al.

Correspondence to: Weixing Zhu (wxzhu@binghamton.edu) and Yunting Fang (fangyt@iae.ac.cn)

The copyright of individual parts of the supplement might differ from the CC-BY 3.0 licence. 
Supplementary Figure legends:

36

37 Figure S1 Climate variables. The positive correlation (b) between aridity index (AI) and precipitation demonstrated that the precipitation gradient here can also be considered as an AI gradient. At each site, 39 $\mathrm{n}=1$.

40

Figure S2 Soil moisture along the precipitation gradient. Soil moisture was expressed as a percent of dry 42 soil on a mass basis. At each site, $\mathrm{n}=5$.

43

44

45

46 


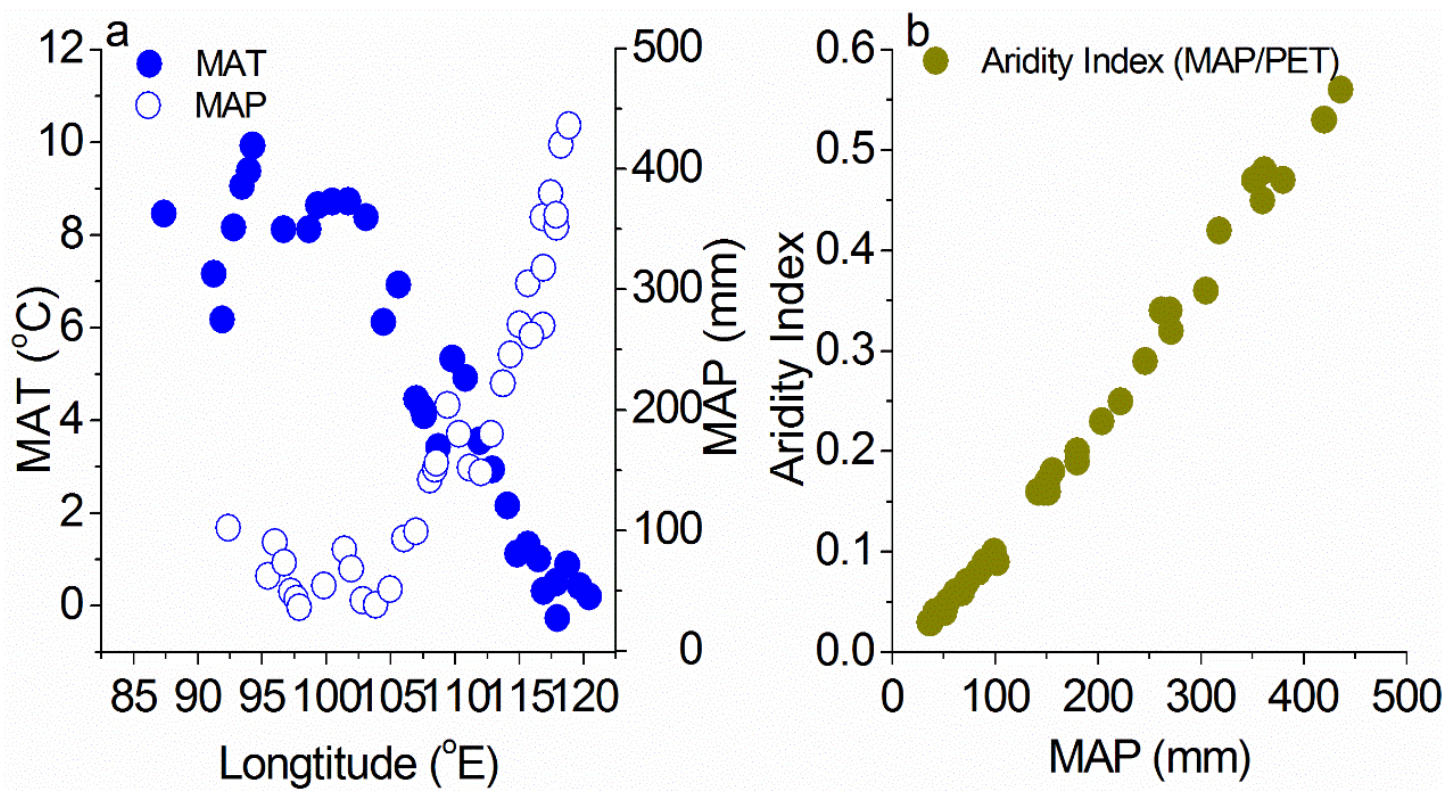

Figure S1 


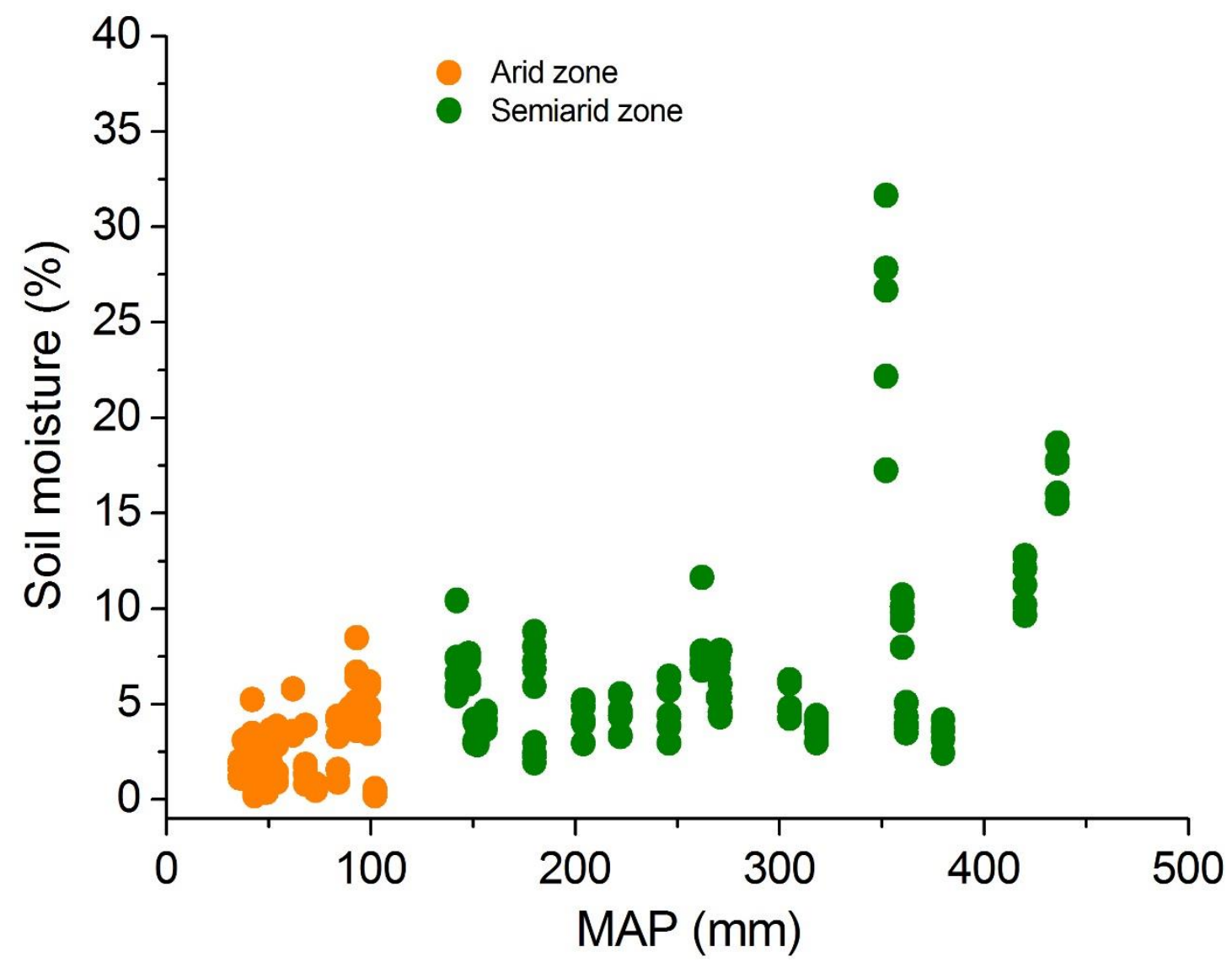

Figure S2 